\section{Flexible, stable interdental brushing}

As patients are discovering the value of interdental brushing, they will be looking for the best brush to use.

Why choose TANDEX FLEXI? Well, it's flexible and stable, with an adjustable softgrip handle that feels nice to hold. With coated wires, they will glide through interdental spaces easily and gently.

In nine sizes, patients can find the right one for them, that will gently remove deposits from between the teeth. And, once they've been shown how, they will find it easy to use every day.

Contact TANDEX to offer these premium tools in your practice.

For more information on Tandex's range of products visit www.tandex.dk.

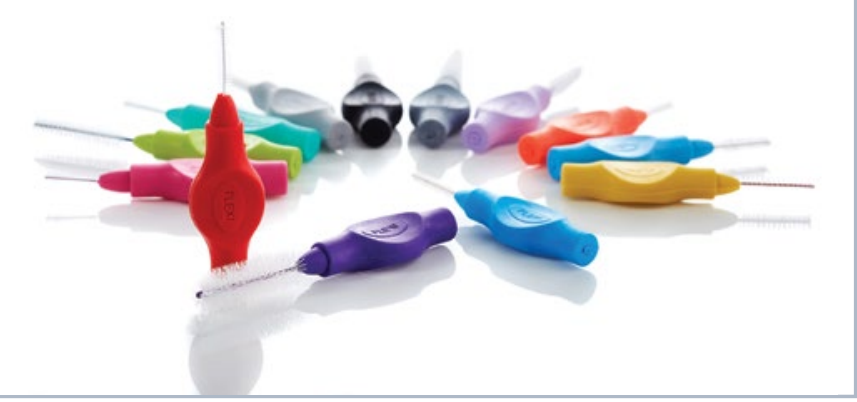

\section{Evolve with technology}

Evolve your practice, increase patient interest and gain a competitive edge with the revolutionary CALCIVIS imaging system.

Using bioluminescence to visualise active demineralisation on the surfaces of the teeth, the CALCIVIS imaging system enables practitioners to see the very early signs of the caries disease process in time to initiate first response, reparative therapy.

The evidence-based CALCIVIS images allow patients to better understand their oral health and empower them to take preventive action to avoid further damage to the teeth.

The CALCIVIS imaging system has the potential to generate additional revenue and facilitate further investment and progression. Contact the team now to find out how.

For more information visit www.calcivis.com, call 0131658 5152 or email info@calcivis.com - all claims are relevant to UK dentistry.

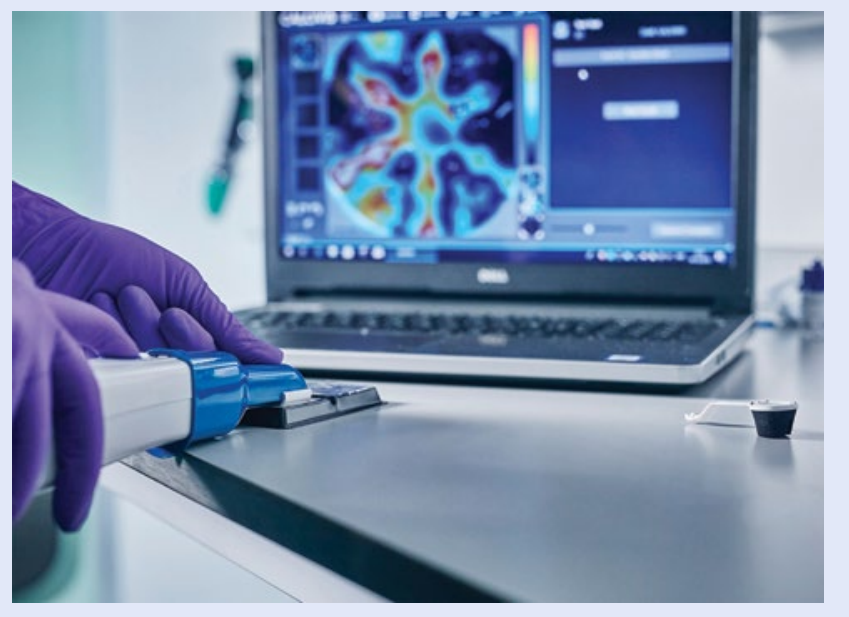

\section{The reliable restorative option}

If you're after excellent mechanical retention in dentine for composite, amalgam or another core material when providing restorations, try Stabilok Dentine Pins, manufactured by Fairfax Dental Ltd in the UK.

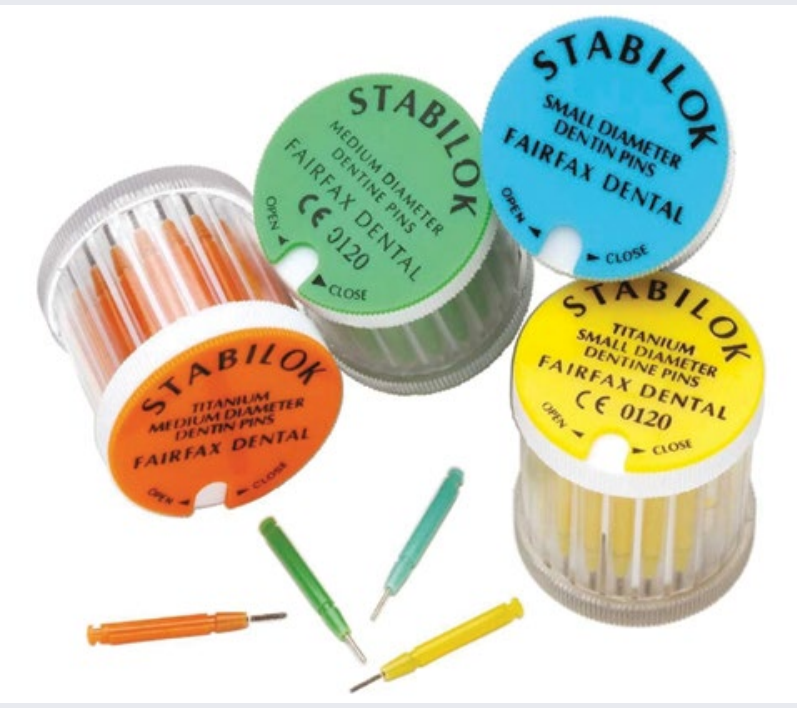

Stabilok Dentine Pins have been used to retain and support cast restorations placed indirectly by retaining the restorative core material in extensively damaged teeth in operative dentistry for the last 45 years.

The Stabilok pins are self-threading and self-shearing, which are engineered to fit into contra-angle slow speed handpieces and to be placed easily into pre-drilled holes at $2 \mathrm{~mm}$ depth. The strict placement depth of $2 \mathrm{~mm}$ pins is governed by the Stabilok Twist Drill, significantly reducing the risk of fracture in dentine and making it a very cost effective, easy and effective method for restoration.

For more information, call 02089476464.

\section{Intensive cadaveric training with leading surgical trainers}

Professor Cemal Ucer and Professor Andrea Tedesco - both Specialist Oral Surgeons and renowned for their skills and experience in dental implantology - will be presenting a new training course this spring.

The intensive hands-on surgical training will teach zygomatic, nasal and pterygoid implant placement for the treatment of the severely atrophic maxilla. It will cover using both conventional and the Zygomatic Minimally Invasive Technique (ZMIT) with piezo electric instrumentation, which was developed by Professor Tedesco himself and presented at the International Zygomatic Congress in London 2019.

For dentists experienced in dental implantology and looking for safe and effective zygomatic solutions for a wide range of complex clinical situations, this course is for you.

The course will take place on 30 April - 1 May 2020 in Manchester. To book, email ice@ucer.uk or call Mel Hay on 0161237 1842. www. ucer.education. 